\title{
Urgences
}

\section{Les Orphelins de Hoi Tri}

\section{Jean-Pierre April}

Numéro 3, 4e trimestre 1981

URI : https://id.erudit.org/iderudit/025039ar

DOI : https://doi.org/10.7202/025039ar

Aller au sommaire du numéro

Éditeur(s)

Urgences

ISSN

0226-9554 (imprimé)

1927-3924 (numérique)

Découvrir la revue

Citer ce document

April, J.-P. (1981). Les Orphelins de Hoi Tri. Urgences, (3), 17-22.

https://doi.org/10.7202/025039ar

Ce document est protégé par la loi sur le droit d'auteur. L'utilisation des services d'Érudit (y compris la reproduction) est assujettie à sa politique d'utilisation que vous pouvez consulter en ligne.

https://apropos.erudit.org/fr/usagers/politique-dutilisation/
Cet article est diffusé et préservé par Érudit.

Érudit est un consortium interuniversitaire sans but lucratif composé de l’Université de Montréal, l'Université Laval et l'Université du Québec à Montréal. Il a pour mission la promotion et la valorisation de la recherche. https://www.erudit.org/fr/ 
JEAN-PIERRE APRIL

Les Orphelins de Hoi Tri 
On n'a jamais eu si bonne raison d'affirmer que les enfants constituent la principale richesse des pays sous-développés...

Mais chez-nous, la plupart des parents qui avaient survécu au géno étaient si marqués par les massacres qu'ils ne parvenaient plus à élever leurs enfants, qui jouaient aux soldats à travers les décombres tout chauds.

Juste avant l'extermination totale, I'opinion publique fut alertée, le Club de l'Homme intensifia ses pressions, quelques diplomates en profitèrent pour hausser leur prestige au sein de I'ONU, et à quelques minutes près, une réunion secrète des principaux stratèges, télédiffusée en direct par satellite, avait sauvé l'ultime bastion de Hoi Tri.

Je me souviens qu'on ne voyait plus les grands soldats blêmes dans la ville. La guerre était finie, les cuirassés partis, et les prostituées retournaient dans les rizières ou dans leur village dévasté par le napalm, en amenant leurs enfants à la peau noire ou aux cheveux pâles. $\dot{A}$ notre âge, seuls le chewing-gum et surtout les nombreux films de brigands et de héros restaient en souvenir de leur passage, pour aiguiser notre frénésie de gamins survoltée par le carnage où nous étions nés...

Malgré sa main droite emportée par une grenade, mon père persistait à parcourir le port à la recherche d'un emploi de coolie ou de marin. Mais les pêcheurs affairés l'ignoraient poliment, ou déposaient une bouteille d'alcool dans sa main valide, et mon père les saluait du moignon quand ils s'empressaient de lancer leur jonque dans le golfe du Tonkin.

Pendant des jours, il avait erré à la recherche de nourriture; il partait avec les plus vieux des enfants, qui suffisaient à peine à calmer leur propre appétit. Quelques-uns rechignaient à l'idée de 
servir la ribambelle d'enfants osseux, encore trop jeunes pour se débrouiller, et certains d'entre eux, pourtant parmi les plus débrouillards, étaient disparus à tout jamais... Mon père maigrissait autant que nous, sans pouvoir tirer suffisamment de ressources des ruines toujours fumantes.

Un bon soir, alors qu'il avait bu plusieurs bouteilles d'alcool de riz, il avait provoqué en duel tous les garçons qui hésitaient encore entre l'univers de l'enfance et la jungle des adultes. II avait besoin de diminuer la famille. Ainsi, tous ceux qui lui offriraient suffisamment de résistance seraient déclarés en âge de partir. Les estropiés resteraient.

Ma force m'a perdu. Le lendemain, il m'a accompagné pour la dernière fois dans les bas-fonds de la ville où il m'a égaré. II $\mathrm{m}^{\prime} \mathrm{a}$ indiqué la zone où nos alliés avaient construit leurs usines, là où je pourrais faire mon chemin, puis il a caressé ma mâchoire cassée, silencieusement, et il s'en est retourné en me laissant seul, à la merci de cette nouvelle classe d'adolescents abandonnés qui pillaient les quartiers reconstruits par les ouvriers spécialisés. Ces bandes rivales de jeunes sauvages aux noms poétiques et agressifs prenaient bien soin de surveiller leur aspect rebelle; elles opéraient à la façon des bandits longuement observés à la télévision, un autre cadeau de nos alliés blancs.

Dans le labyrinthe des docks, où se tenait le gang qui m'avait adopté après une seconde cassure de la mâchoire, nous vivions en assez bons termes avec les adultes, trop empressés par les sifflets d'usine pour penser à chasser les Dragons Blindés. À la condition d'éviter les chauffeurs de taxi, qui cherchaient à prendre le monopole des trafics plus ou moins clandestins de la ville, nous pouvions mener une véritable vie d'aventure, qui satisfaisait pleinement nos idéaux de héros télévisés.

Au moins ils nous laissaient regarder leurs boîtes à images qu'ils entassaient dans les vitrines des grands magasins. À chaque soir, quand nous étions fatigués de vagabonder sur la rue principale hérissée de nouvelles façades de verre scintillant et de métal clinquant, nous nous entassions devant ces téléviseurs qui diffusaient plusieurs films à la fois. Enfin, quand l'employé venait éteindre les appareils, nous retournions à nos refuges en rêvant 
de vengeances cinématographiques.

Blottis dans des grottes formées par les trous de bombes, ou allongés dans des carcasses d'autos abandonnées au fond des terrains vagues, nous pouvions dormir en toute sécurité. Bien sûr les adultes tentaient toujours de nous escroquer, en voulant nous échanger quelques bières pour les rétroviseurs, les radios ou les batteries que nous essayions de leur vendre, mais après tout c'était là des trucs qui leur étaient volés.

Et si jamais un Dragon Blindé voulait acheter un beau collier à sa copine, ou s'il perdait une grosse mise sur un combat de chiens, alors il pouvait toujours travailler aux égouts pour se renflouer.

La nouvelle prospérité occupait tout le pays. Les adultes ne songeaient même pas à nous chasser, ni à nous éduquer. Peutêtre le remords de leur abandon les porta-t-il par la suite à nous faire des largesses... Ainsi, quand le mal à I'âme nous montait à la gorge, quand nous traînions nos talons nus en tournant en rond sur les larges trottoirs de ciment du Hoi Tri-by-night, ils nous permettaient d'aborder leurs belles autos reluisantes arrêtées aux feux de circulation; nous approchions les lèvres des tuyaux d'échappement brûlants, le temps de pomper une bonne bouffée de gaz, la lumière passait du rouge au vert, puis ils repartaient à leurs rendez-vous, pendant que notre ennui s'effilochait dans l'ivresse de minuit...

Quand les néons faiblissaient dans l'aurore, on s'éveillait, affalés sur un trottoir, on dégueulait, un nouveau jour naissait, et le soir suivant on recommençait...

Autrefois, à l'époque où Tchien maîtrisait le trafic du port, chaque nuit nous donnait l'occasion de sortir des canalisations pour piller quelques cales; nous aimions piger les gadgets les plus hétéroclites, qu'ils fabriquaient pour les pays blancs des riches continents. Souvent nous passions des heures à jouer comme des enfants normaux avec des babioles bruyantes, qu'il nous fallait briser pour en trouver l'utilité. Après ces fêtes, nous oubliions le butin et le profit, pour repartir généralement en délaissant nos jouets éventrés dans le soleil levant. 
Mais aujourd'hui nous sommes foutus.

Depuis que leurs médecins ont découvert le moyen de pâlir la pigmentation des enfants naissants, et de leur arrondir la fente des yeux, le Bureau d'Adoption des continents blancs fait concurrence au recrutement de nos gangs. Les Dragons Blindés ne se reproduisent plus...

Maintenant que les nouveaux-nés valent un prix d'or sur le marché blanc de l'hémisphère nord, au lieu de les abandonner, les pères déshérités préfèrent les vendre. Alors les Taxis ne craignent plus les représailles de notre troupe déclinante. Quand un Dragon isolé longe une ruelle mal éclairée, ils ne se gênent pas pour lui écraser les tibias sous leurs pare-chocs. D'ailleurs ils possèdent déjà le contrôle du détroussage, de la drogue et de la délation. En passant par eux, vous pourriez même adopter un beau bébé blanc, à meilleur prix et dans des délais plus rapides que ceux promis par le Bureau d'Adoption...

Ce matin, Hia s'est fait 300 U.S. dollars en leur remettant le bébé que je lui ai fait. C'est plus que tout ce que j'ai pu récolter dans les neuf derniers mois de vol à l'étalage. Alors nous avons fêté ça avec une bouteille de gin importée de leur pays.

Ensuite je me suis acheté des vêtements occidentaux et je me suis cherché un emploi. J'avais beaucoup d'expérience dans les docks, mais avec ma carte d'orphelin, quel patron aurait pu me faire confiance?

Aucun. Dorénavant seuls les éboueurs licenciés, ceux qui sont passés à leur école, peuvent travailler. II faut savoir lire pour balayer les ordures.

Les taxis nous ont volé notre clientèle; ils contrôlent maintenant notre dernière chasse-gardée, le recel. Et quand les policiers nous aperçoivent après la tombée du jour, ils lancent leurs bergers-allemands à nos trousses. Même qu'en plein jour, si un rebelle oublie de se promener en gang, les jeunes écoliers l'attendent au coin des ruelles pour lui donner une volée de coupsde-poings américains. 
S'il nous reste un peu de chance, nous attrapons un chat dans les faubourgs et nous nous le faisons rôtir sur des charbons qui traînent au fond des chantiers de construction. Mais les organismes de protection commencent à nous poursuivre, ils cherchent à nous enfermer dans leurs institutions de réhabilitation. Même les reporters étrangers ne veulent plus payer pour nous photographier devant les façades des vieilles boutiques épargnées par les bombes, puis par les marteaux des démolisseurs. Nos binettes sales ne cadrent plus dans le progrès. Nous faisons peur aux touristes. À seize ans, nous sommes dépassés par les événements, nous ne pouvons plus continuer cette course sans débouché, qui finit par étouffer notre romantisme juvénile dans un corps d'homme qui nous embarrasse.

Bientôt, nous nous lassons de l'oxyde de carbone pompée à la sauvette aux carrefours achalandés; le gaz ne fait plus qu'envenimer une migraine permanente.

Les travailleuses sociales nous donnent le choix entre l'école de réforme et la manufacture. Sinon c'est la prison.

Mais dans la plupart des cas, quand ils parviennent à prendre un des nôtres pour un des leurs, après lui avoir bien appris à manier des ustensiles de métal et à marcher dans des souliers serrés, ils ne font que provoquer chez-lui l'ultime geste de rébellion d'un mésadapté foncier. Tôt ou tard le jeune insoumis ne se reconnaît plus. Les bonnes manières le minent. II ne parvient plus à réveiller ce rire sauvage qui nous prenait en groupe au coin des rues bruyantes et confuses. Si jamais il rencontre un jeune révolté en liberté, il panique. Et alors, avant qu'il n'ait éteint toute sa soif de liberté, il se laissera tomber devant le pare-chocs d'un trolleybus, ou d'un Taxi... hara-kiri quotidien des jeunes survivants de la guerre, morts au front de la civilisation.

J'en suis là. Adieu Hia. J'espère seulement que notre bébé blanc jaunira avec le temps. 